\title{
Melatonin as a powerful antioxidant
}

AGNIESZKA CHRUSTEK*

DOROTA OLSZEWSKA-SŁONINA

Department of Pathobiochemistry and Clinical Chemistry, Faculty of Pharmacy L. Rydygier Collegium Medicum Bydgoszcz, Nicolaus Copernicus University, Torun, Poland
Accepted September 18, 2020

Published online October 18, 2020

\begin{abstract}
Melatonin is a hormone that has many body functions and, for several decades, its antioxidant potential has been increasingly talked about. There is a relationship between failure in melatonin production in the pineal gland, an insufficient supply of this hormone to the body, and the occurrence of free radical etiology diseases such as neurodegenerative diseases, cardiovascular diseases, diabetes, cancer and others. Despite the development of molecular biology, numerous in vitro and in vivo studies, the exact mechanism of melatonin antioxidant activity is still unknown. Nowadays, the use of melatonin supplementation is more and more common, not only to prevent insomnia, but also to slow down the aging process and provide protection against diseases. The aim of this study is to get acquainted with current reports on melatonin, antioxidative mechanisms and their importance in diseases of free radical etiology.
\end{abstract}

Keywords: melatonin, antioxidants, lipid peroxidation, free radicals, oxidative stress

\section{INTRODUCTION}

Melatonin (N-acetyl-5-methoxytryptamine), an indoleamine that was first isolated from pineal pinealocytes in 1958 by Lerner et al. (1), is named because of the effect it causes on the amphibian pigment found in the skin of amphibians and reptiles. It is suggested that melatonin is the oldest signal molecule on Earth. It occurs in vertebrates, invertebrates, bacteria, yeasts, plants, as well as in algae. In herbs used in Chinese medicine, its content varies from 10 to $4000 \mathrm{ng} \mathrm{g}^{-1}$ dry matter, which is why they were used to delay aging processes and to treat diseases with free radical etiology (2). It is synthesized mainly by the pineal gland but it is also produced by the digestive system, blood cells, lens and retina of the eye, kidneys, thyroid, ovaries, cerebellum, bile, bone marrow and cerebrospinal fluid (2). The level of the hormone in the blood changes cyclically throughout the day since light inhibits the melatonin biosynthesis $(1,2)$. In addition, the concentration of melatonin depends on season and age. Scientific research has shown that the production of extrapineal melatonin is not light-dependent (2). During the night, the concentration of melatonin in human plasma is high and amounts to ca $120 \mathrm{pg} \mathrm{mL}^{-1}$ while, during the day, it decreases significantly to the value of about $10 \mathrm{pg} \mathrm{mL}^{-1}$. The crossing of melatonin

\footnotetext{
*Correspondence; e-mail: agnieszka.chrustek@gmail.com
} 
through the placental barrier is one of the signal mechanisms that synchronize the mother's biological clock with the fetus's. The circadian rhythm of melatonin occurs between the age of 6-9 weeks, whereas the distinct circadian rhythm is formed in the newborn within 3-4 months of life, after which its nocturnal level increases, reaching the highest values at the age of 3-6 years. Human infants' melatonin levels become regular in about the third month after birth, with the highest levels measured between midnight and 8:00 a.m. Stabilization of the hormone is visible at the age of 35-40. After the age of 40, the concentration of melatonin decreases, which may lead to disturbances in the proper body function. Due to the lipophilic structure, melatonin penetrates all biological barriers in the body and also interacts with several biochemical pathways and affects tissues and cells (2). This hormone is also found in human milk and according to Illnerova et al. (3) melatonin concentration is of the order of $99 \pm 26 \mathrm{pmol} \mathrm{L}^{-1}$. Katzer et al. (4) compared the concentration of breast milk from night and day batches. Higher melatonin concentration was found in human milk at night $\left(7.3 \mathrm{pg} \mathrm{mL}^{-1}\right)$ than in the day $\left(1.5 \mathrm{pg} \mathrm{mL}^{-1}\right)$. It is assumed that melatonin circulating in the blood during the day comes from the gastrointestinal tract, where the content of this hormone is 400 -fold higher than in the pineal gland, and the concentration 10-100 times higher than in the plasma (5). In contrast, the level of melatonin in the cerebrospinal fluid of the lateral ventricles is 5-10 times higher than in serum (5).

\section{HOW DOES MELATONIN FUNCTION?}

Melatonin works in a cell in four ways: by binding to membrane receptors, through interaction with nuclear receptors, through direct binding to cytoplasmic proteins and as an antioxidant (6). The main mechanism of action of melatonin is the interaction with melatonin receptors which are found in the cells of the nervous system, the retina of the eye, kidneys, gastrointestinal tract, liver, gonads, heart, prostate gland, skin and immune system (6). Melatonin receptors, MT1, MT2 and MT3, affect the functioning of ionic channels, second messenger levels and the expression and activity of many protein enzymes. MT1 and MT2 receptors belong to the superfamily of receptors conjugated with G proteins, the so-called G-protein-coupled receptors (GPCR), whereas MT3 belongs to the family of quinone reductases, but has not been identified in mammals (7). Melatonin may affect a number of secondary relays such as cyclic adenosine monophosphate (cAMP), cyclic guanosine monophosphate (cGMP), inositol trisphosphate (IP3), diacylglycerol (DAG) or arachidonic acid (6). Indoleamine can also bind to retinoic acid receptor-related orphan receptor/retinoid $\mathrm{Z}$ receptor (ROR/RZR). ROR- $\alpha$ occurs in the central nervous system (CNS), brown adipose tissue, liver, testicles and skin, ROR- $\beta$ mainly in the CNS, ROR-y in skeletal muscles (6). These receptors affect the development of CNS and the immune system, regulate circadian rhythm and participate in cell differentiation and proliferation. Melatonin also affects cells by combining with intracellular proteins, e.g., calmodulin $(6,7)$.

\section{MELATONIN SYNTHESIS}

The synthesis of melatonin begins with hydroxylation of tryptophan followed by decarboxylation with the participation of 5-hydroxytryptophan 5-hydroxylase and 5-hydroxytryptophan decarboxylase, which leads to the formation of serotonin $(6,8)$. Serotonin is acetylated by serotonin $N$-acetyltransferase (NAT) followed by methylation by hydroxy- 
indole-O-methyltransferase (HIOMT). This is how $N$-acetyl-5-methoxytryptamine, or melatonin, is formed. The resulting compound is released into the blood and its half-life is about 2-20 min. Melatonin is metabolised in the liver by cytochrome P450 and its metabolites are removed by kidneys. Melatonin metabolites include: 6-hydroxymelatonin, 3-hydroxymelatonin, 6-sulfotoximelatonin, cyclic 3-hydroxymelatonin, $N^{1}$-acetyl- $N^{2}$-formyl-5-methoxykynuramine (AFMK) and to a lesser extent $N^{1}$-acetyl-5-methoxykynuramine (AMK). In mammals, the biosynthesis of the pineal melatonin is regulated by a superior biological clock, located in the suprachiasmatic nucleus of the hypothalamus (SCN) (6-8).

Studies of melatonin in plants have a much shorter history since this substance has been identified in plants in 1995 (9). The indolamine synthesis is much higher in plants than in animals. Plants synthesize tryptophan via the shikimic acid pathway, and thus the ability to synthesize melatonin is not limited by the availability of tryptophan in their environment. In plants, tryptophan is first decarboxylated and then hydroxylated, inversely to animals. Under normal conditions, the synthesis process takes place in chloroplasts, however, when the processes are blocked, then the synthesis pathway takes place in the mitochondria (9).

\section{FUNCTIONS OF MELATONIN}

Currently, melatonin is used as a sleeping remedy (10). It is used as a supplement and as a drug in sleep disorder associated with the change of time zones and shift work, as well as in the disturbance of the circadian rhythm of sleep and wakefulness in blind patients. Geriatric patients are also increasingly reaching for indoleamine. Many studies confirm the beneficial effect of melatonin on various diseases (10). Melatonin works paracrine, autocrine, endocrine and has anti-inflammatory activity $(2,10)$. It regulates circadian rhythm and affects reproductive activity in mammals through the secretion of hormones of the hypothalamus, pituitary gland and gonads. It regulates the secretion of hormones such as prolactin, lutropin, follitropin, somatotropin and adrenocorticotropin. It participates in the regulation of the immune system by increasing the activity of NK cells, phagocytes, as well as the synthesis of IL-2, IL-6, and IFN- $\gamma$ by mononuclear cells (2). It plays an important role in disorders of the digestive system (peptic ulcer, hypersensitive bowel syndrome) and affects glucose metabolism (8). It protects the cardiovascular system through changes in hypertension thanks to its antioxidant and antilipid properties. There are reports of its impact on mental and neurological diseases, due to its neuroprotective effect $(8,11)$. For many years, we have been talking about anticancer and oncostatic properties of melatonin that inhibits the activation and proliferation of cancer cells $(12,13)$. This refers to melanoma, glioma, breast cancer, lung, liver, kidney, ovary or bladder cancer. In vitro or in vivo administration of melatonin results in inhibition of tumor growth and induction of tumor cell apoptosis. Melatonin regulates pro-apoptotic and anti-apoptotic factors in normal conditions and during oxidative stress. In addition, studies are suggesting a beneficial effect of melatonin on the infant's colic stitches (14).

\section{Antioxidant effect}

Scavenging of reactive oxygen species by melatonin and its metabolites. - The melatonin molecule is soluble in water as well as in fats, therefore, it can act as an antioxidant both in 
the aqueous environment inside the cell and in body fluids, as well as in the cell membranes and cell organelles (9). Melatonin causes a reduction in oxidative stress. It is believed that its antioxidant effect is much stronger than vitamins $\mathrm{E}$ and $\mathrm{C}$, and glutathione. The molecule can capture up to 10 ROS (reactive oxygen species) compared to classic antioxidants that neutralize one or less ROS (9). The protective effect of melatonin is to increase the activity of antioxidant enzymes, including superoxide dismutase (SOD), catalase (CAT) and glutathione peroxidase (GPx) by increasing the expression of the above-mentioned enzymes (7). Elevated levels of CAT mRNA, SOD and GPx as a result of melatonin were observed. In addition, indoleamine reduces the activity of pro-oxidative enzymes such as nitric oxide synthase. The best effects were observed in conditions where the hormone concentration was physiological or near physiological. Indoleamine increases the activity of $\gamma$-glutamylcysteine synthetase, glutathione reductase and glutathione transferase, which participate in the synthesis of glutathione. Additionally, melatonin is located on the surface of cell membranes near the polar heads of phospholipids, consequently protecting the cell membranes against oxidation. By changing the fluidity of the membranes, it removes radicals before they damage the lipids and proteins of the cell membrane. Melatonin has no pro-oxidative properties (7).

Melatonin is a potent radical scavenger and electron donor for highly reactive free radicals because it is a molecule rich in electrons (9). It can neutralize species like hydroxyl radical, hydrogen peroxide, singlet oxygen, nitric oxide, hypochlorite and peroxyl radical (9). The reaction product of melatonin with a hydroxyl radical is 3-hydroxymelatonin excreted in urine (7). Melatonin removes singlet oxygen at a constant rate of $2.2 \times 10^{7} \mathrm{~L} \mathrm{~mol}^{-1} \mathrm{~s}^{-1}$ (15). This molecule probably does not have the capacity to remove superoxide anion radicals. Melatonin combines with a hydroxyl radical to give a compound that combines with the superoxide anion radical to form $N^{1}$-methyl- $N^{2}$-formyl-5-methoxykynuramine. AFMK may undergo a catalytic reaction by catalase and leads to the formation of $N^{1}$-acetyl-5-methoxykynuramine. The removal of hydrogen peroxide depends on the concentration of the hormone and the molecule is converted into AFMK. This process takes place in two stages; in the first stage, the reaction rate is constant and amounts to $2.3 \times 10^{6} \mathrm{~L} \mathrm{~mol}^{-1} \mathrm{~s}^{-1}$, the second stage is much slower. Melatonin removes nitric oxide at a rate of $3.0 \times 10^{7}$ $\mathrm{L} \mathrm{mol}^{-1} \mathrm{~s}^{-1}(16)$.

Metabolites of melatonin also have an antioxidant effect (9). Several studies have shown that cyclic 3-hydroxymelatonin is a stronger antioxidant than melatonin itself and causes the capture of the hydroxyl radical and other ROS; AMK and AFMK have antioxidant properties as well (9).

\section{Activation of elements of the antioxidant response}

One of the latest reports of antioxidative mechanisms of melatonin is its action by activating the ARE system, increasing Nrf2 levels and inhibiting NF- $\kappa B$ activity (17). Activation of elements of the antioxidant response (ARE) leads to the transcription of many antioxidant proteins and enzymes that process reactive oxygen species and transport proteins. The nrf2-ARE pathway may stimulate the activity of antioxidant enzymes, such as SOD, CAT, GPx, homooxygenase-1 (HO-1), quinone oxidoreductase (NQO1), sulfadoxine (Srx), thioredoxin reductase (Txnrd), glutathione S-transferase (GST) (17-19). Activation of the Nrf2-ARE pathway contributes to protection against various diseases, i.e., cardiovascular diseases, neurodegenerative diseases (i.e., Alzheimer's disease, Parkinson's disease, 
Huntington's disease, multiple sclerosis), cancer, but it can also protect cancer cells against therapy $(19,20)$. Melatonin increases Nrf2 levels in cells during oxidative stress (19). Deng et al. (21) presented studies in which the action of melatonin is associated with the Nrf2 transcription factor and its translocation to the nucleus and interaction with ARE. In contrast, Ding et al. (22) observed an increase in the concentration of Nrf2 in the nucleus of mice subjected to traumatic brain injury, along with the increase in the transcription of antioxidant enzymes, i.e., HO-1, NQO1, GPx, SOD. Subsequent studies have shown that melatonin alleviates the effects of stress and alcohol consumption by protecting the hippocampus of the brain, and regulates the Nrf2/H0-1 path (23). Additionally, melatonin inhibits the activity of NF- $\mathrm{BB}(19)$. There is little research on this topic, but it is likely that melatonin increases the concentration of I $\kappa \mathrm{B}-$ alpha (NF- $\kappa \mathrm{B}$ inhibitor). Aparicio et al. (24) presented studies on mouse macrophages in which they demonstrated the effect of melatonin on the NF- $\kappa \mathrm{B}$ cascade and the Nrf2 pathway. Peritoneal macrophages from mice were isolated and treated with melatonin at 12.5, 25, 50 and $100 \mu \mathrm{mol} \mathrm{L}^{-1}$ in the presence or absence of $5 \mathrm{mg} \mathrm{mL}^{-1} \mathrm{LPS}$ for $18 \mathrm{~h}$. Melatonin reduced the levels of nitrites, iNOS, COX-2, mPGES-1, phosphorylation of p38 MAPK, and prevented the translocation of NF- $k B$. Melatonin reduces pro-inflammatory mediators and increases expression of HO1 through the NF- $\kappa$ B cascade, p38 MAPK and Nrf2 signaling pathways in mouse macrophages. Melatonin has proven to be a promising therapeutic for diseases associated with over-activation of macrophages.

\section{MELATONIN - USE AND ANTIOXIDANT PARAMETERS}

\section{Animal model}

Effect of melatonin on the disease treatment. - Research on animal models is an important element in research. Researchers are extensively studying the effects of melatonin in vivo. Brazao et al. (25) evaluated the immunological and antioxidant changes caused by aging and infection due to Trypanosoma cruzi. Rats infected with T. cruzi and treated with melatonin showed increased activity of SOD and GSH in plasma as well as high levels of CD4 ${ }^{+}$ CD28-negative $\mathrm{T}$ cells and reduction of CD28-negative in $\mathrm{CD} 4^{+}$and $\mathrm{CD} 8^{+} \mathrm{T}$ cells. However, in subsequent studies on rats with oxidatively damaged thymus, an increase in SOD and a decrease in antibodies against the thyrotropin receptor (TRAb) after indoleamine administration were observed. There was an increase in thymus and an increase in thymocytes. Melatonin is shown to be useful in the treatment of Chagas disease. An interesting observation is also the protection by melatonin in mastitis, consisting of antioxidant and antiinflammatory effects.

In many studies with melatonin treatment, a decrease in malondialdehyde (MDA) is observed, suggesting protection against lipid peroxidation (26-28). The aqueous buffalo was injected subcutaneously with $18 \mathrm{mg}$ melatonin per $50 \mathrm{~kg}$ body mass, then blood samples were taken and analyzed for MDA, NO and total antioxidant capacity (TAC). The results show an increase of TAC, a decrease of MDA, and $90 \%$ induction of estrus in treated animals indicating improvement of fertility (26). Another study was presented by Onk $e t$ al. (29), who evaluated the beneficial effects of melatonin in the treatment of diabetes. Rats with induced diabetes by using streptozocin were treated with melatonin at a dose of 20 $\mathrm{mg} \mathrm{kg}^{-1}$ body mass per day. Melatonin reduced the level of MDA and myeloperoxidase 
(MPO) to a normal level (control group). In addition, decreased expression of cleaved caspase-3 was observed. Higher MDA values after indoleamine treatment were also observed in PC (pulmonary circulation) contamination caused by isolated blunt chest trauma in rats. Moreover, higher total antioxidants capacity values and reduction of histopathological lesions were observed, including protective effects on distant organs, for example, liver and kidneys, by reducing oxidative stress (30). Melatonin also reduces the level of MDA and increases the activity of SOD and CAT in Chhotanagpuri sheep (31).

Melatonin can be an effective and promising therapeutics in liver diseases including ischemia-reperfusion injury (IRI), non-alcoholic fatty liver disease (NAFLD), non-alcoholic steatohepatitis (NASH), hepatic fibrosis, hepatic cirrhosis and hepatocellular carcinoma (HCC) (32-34). Animal studies have shown a reduction in MDA and an increase in SOD, CAT, and GSH in animals treated with melatonin with induced liver damage (32). In contrast, Chen et al. (33) demonstrated a decrease in NOX1, NOX2, NF- $\kappa$ B protein expression in the liver and an increase of HO-1 NQO-1 protein expression in IRI rats. Kireev et al. (34) showed reductions in MDA4-HDA and cytosolic NOx in rats with IRI, as well as increases in GPx, GSH/GSSG and GST. The protective role of melatonin in the liver fibrosis was demonstrated by Mortezaee et al. (32). They described the reduction of MDA and an increase in SOD, GPx. In addition, subsequent scientists have demonstrated protection against cirrhosis by reducing TBARS and increasing SOD, GPx GST and CAT (35). Melatonin has strong antioxidant properties that can help restore liver function after ischemiareperfusion injury (36). After treatment with melatonin, an increase in the activity of antioxidant enzymes, including SOD and GSH, as well as a decrease in ALT, AST and LDH levels were observed.

Indoleamine also has a protective effect on other organs such as the thyroid, larynx, kidneys and pancreas (36-41). Melatonin reduces hyperthyroidism induced by oxidative stress in hamsters and decreases nerve cell death in the region of the hippocampus of the brain. This may be important in cognitive and memory disorders in women with hyperthyroidism. A decreased level of TBARS and increased activity of antioxidant enzymes was observed (37). Melatonin also protects the pancreas from damage by reducing oxidative stress and increasing the activity of antioxidant enzymes in acute pancreatitis caused by cerulein in Wistar rats. Indoleamine prevents lipid peroxidation (decrease of MDA), protein oxidation and directly and indirectly can stimulate the expression of antioxidant enzymes (38). Melatonin has antioxidant and anti-inflammatory effects in the functioning of the kidneys. Ashen et al. (39) described the action of the hormone on kidney damage developed after subrenal aortic retention in rats. It was observed that melatonin had a beneficial effect on damaged kidneys caused by aluminum and hypertension (40). Subsequent research presents a very important aspect nowadays, due to the large population of smokers in the world. Smoking causes pathological changes in the mucous membrane of the larynx and the development of tumors. Studies in rats have shown that melatonin may, to a certain extent, suppress adverse effects, which may be important for smokers (41).

A number of studies on animal models show that melatonin can be used as a therapeutic agent in the treatment of brain damage $(42,43)$. Ischemic areas have been shown to decrease significantly after using melatonin. Venezuelan equine encephalitis leads to apoptosis and induces an anti-inflammatory response by increasing CD200 expression. Mice infected with the above-mentioned virus were tested and increased animal survival by $25 \%$, decreased apoptosis and CD200 expression were observed (42). 
The central nervous system and the brain are susceptible to oxidative stress, which can lead to stroke (44). Delivery of antioxidants such as melatonin may prevent the formation of oxidative stress. Melatonin acts as a scavenger of free radicals and as an indirect antioxidant. It removes hydroxyl radicals generated by Fenton's reaction and reduces lipid peroxidation in the brain and also blocks toxicity induced by singlet oxygen. Studies in rats with induced stroke and removed pineal glands have shown that the use of melatonin at a dose of $5 \mathrm{mg} \mathrm{kg}^{-1}$ at the beginning of reperfusion resulted in an improvement in the animals' condition. There was a decrease in ischemic areas in the gray matter and white brain, as well as a reduction in the inflammatory response, reduced brain edema. In addition, in vitro and in vivo studies show the protective effect of melatonin on glial cells.

Protection against toxic effects of chemical compounds causing oxidative stress. - Melatonin protects against the toxic effects of various chemical compounds that cause oxidative stress (45-49). One of such compounds is MK-801 which induces oxidation in the prefrontal cortex of rats causing psychosis (45). There is also an adverse effect of cadmium on the reproductive system in male mice and the mitigation of toxic effects through the use of melatonin. A reduced level of MDA, increased SOD activity, GSH and an increase in TNF-alpha and IL-1 beta were observed (46). Another experience shows that melatonin prevents damage caused by acrylamide. It soothes lipid peroxidation, contributes to the growth of antioxidant enzymes, i.e., SOD, and a lower level of DNA damage in the cerebellum of the rat (47). The cerebellum is exposed to various chemical factors that cause loss of neurons and organ reduction during development. One of the toxic compounds is lead, which causes oxidative stress and neurotoxicity. The effect of melatonin $\left(10 \mathrm{mg} \mathrm{kg}^{-1}\right)$ on lead-induced toxicity in rats was evaluated. A reduction in lipid peroxidation was observed as well as the protection of the cerebellum against lead toxicity (48). Subsequent experiments have shown that melatonin acts neuroprotective on the cerebellum with the toxic effects of ethanol, and reduces the levels of homocysteine (Hcy) in rat plasma (49).

Protection after radiation exposition. - In addition to chemical compounds, animals are exposed to various radiations that melatonin can protect against $(50,51)$. Tropical animals are regularly exposed to UV radiation, which is why the protective effect of melatonin on Funambulus pennanti, which was exposed to UVB $\left(1.5 \mathrm{~J} \mathrm{~cm}^{-2}\right)$, was studied. Melatonin could bind to the melatonin membrane receptor MT1 and the ROR $\alpha$ nuclear receptor. Therefore, after treatment with melatonin, the activity of SOD, CAT, GPx increased significantly. Melatonin increased the activity of antioxidant enzymes and neutralized free radicals to alleviate the damage caused by UVB radiation. UVB radiation indirectly damaged spleen tissue, although the organ was not directly exposed to the harmful factor. Splenocytes apoptosis was observed, while melatonin was followed by the restoration of homeostasis, which consequently prevented the loss of organ function (50). Subsequent studies have shown that melatonin acts as an antioxidant on testicles of rats exposed to microwaves by reducing oxidative stress and DNA fragmentation (51).

\section{Cell lines}

Research on cell lines is the first stage of clinical research. Cell lines are often used in survival and apoptosis studies. Eucaryotic lines treatment as well as cancer cell lines treatment by melatonin are still practiced (52-56). Shu et al. (52) investigated the effect of melatonin on induced pluripotent stem cells iPSC [derived from neuronal stem cells (NSCs)] 
that were exposed to $\mathrm{H}_{2} \mathrm{O}_{2}$. The study used $1 \mu \mathrm{mol} \mathrm{L}-1$ melatonin, $1 \mu \mathrm{mol} \mathrm{L}-1$ melatonin receptor antagonist - luzindole, and $10 \mu \mathrm{mol} \mathrm{L}^{-1}$ phoshatidylinositide-3 kinases (PI3K) inhibitor. The results showed iPSC stimulation with $\mathrm{H}_{2} \mathrm{O}_{2}$, improved stabilization of mitochondrial membrane potential, and decreased apoptosis rate. Treatment with other substances (melatonin receptor antagonist - luzindole, PI3K inhibitor) inhibited proliferation. Melatonin protects NSCs through melatonin receptors and activation of the PI3K/AKT pathway by phosphorylation. This pathway mediates the reduction of cell death and the improvement of cell growth and differentiation. In addition, melatonin treatment reduces DNA fragmentation, weakens caspase-3 activity, and also improves the $\mathrm{Bcl}-2 / \mathrm{Bax}$ ratio.

Subsequent studies showed the protective effect of indoleamine on SH-SY5Y cells (human neuroblastoma cell line) on which methamphetamine (METH) was acting (53). Treatment with melatonin also significantly inhibited the induction of retinal pigment epithelium (RPE) cell damage caused by $\mathrm{H}_{2} \mathrm{O}_{2}$, and decreased apoptosis, increased mitochondrial membrane potential and autophagy (54). A reduced Bax/Bcl-2 ratio increased LC3-II and Beclin-1 protein expression. Additionally, decreased p62 expression was observed.

Oxidative stress participates in abnormalities in nucleus neural precursor cells (NPC) (56). The effect and mechanism of melatonin action on stress-induced oxidative damage to NPCs in rats were investigated. Melatonin has preserved the viability of NPC cells under oxidative stress. Apoptosis index, ROS and MDA levels decreased, but GSH and SOD activity increased. Inhibition of the mitochondrial pathway of apoptosis has been observed (55). Zhu et al. (56) described the use of melatonin in the prophylaxis of intestinal diseases because of its antioxidant capacity. It has been shown to improve immunity to oxidative stress of mice with colitis and regulates intestinal bacterial flora.

Melatonin reverses the damage of $\mathrm{Ca}^{2+}$ absorption in some intestinal disorders that occur with oxidative stress and apoptosis (57). Apoptosis induced by menadione (MEN) in intestinal cells was stopped by melatonin, as indicated by the activity of caspase- 3 and the retention of DNA fragmentation.

Melatonin treatment strengthens the proliferation of peripheral blood mononuclear cells (PBMCs) treated with glucocorticoids (58). Increased dependence of Nrf2/hemeoxygenase-1 (HO-1) and an increase in the Bcl-2/Bax ratio were observed, suggesting that apoptosis is stopped. PBMC treated with melatonin increased the expression and activity of MnSOD and catalase (59). Sanchez et al. (60) noted that melatonin receptors are present in 661W (cone-like photoreceptor cell line) cells. Melatonin can prevent the death of photoreceptor cells induced by $\mathrm{H}_{2} \mathrm{O}_{2}$ by inhibiting the pro-apoptotic Fas/FasL-caspase-3 pathway.

Studies on cell lines suggest that melatonin inhibits apoptosis by affecting proapototic proteins (Bid, Bad, Bax, etc.) and anti-apoptotic (Bcl-2, Bcl-XL, Bcl-w, etc.), which consequently leads to inhibition of apoptosis pathways $(12,13)$.

\section{Research on humans}

Clinical trials on patients are the last stage before the medicine is allowed for sale. Scientific reports suggest that melatonin can be used as a therapeutic in the treatment of diseases with free radical etiology (61-65). Melatonin treatment may be beneficial for patients with metabolic syndrome, especially hypertension (61). Koziróg et al. (61) observed an increase in CAT activity, a decrease in TBARS, improvement of lipid profile, a decrease of LDL-C and a reduction of blood pressure in patients treated with indoloamine. How- 
ever, supplementation with melatonin in obese patients facilitates weight reduction, improves antioxidant defense and regulates the secretion of adipokines (62). An increase in adiponectin of omentin-1 and GPx activity was observed. Examinations in obese women were also conducted by Alamdari et al. (63). The level of TNF-alpha, IL-6 and MDA had decreased, while TAC increased. Diabetes is currently the largest civilization scourge, even in children. Administration of melatonin to patients with non-insulin-dependent diabetes resulted in a significant increase in the morning concentration of melatonin and the activity of SOD1 and also a reduction in the level of MDA (64). Improvement in antioxidant defense has been observed, therefore supplementation of melatonin is suggested as an additional treatment to control the complications of diabetes. Oxidative damage was suggested as the main cause of aging and the development of age-related diseases, including type 2 diabetes (65). The use of melatonin in the elderly at $2 \mathrm{mg}$ and $5 \mathrm{mg}$ per day was studied but there were no differences observed at the level of antioxidant enzymes.

Melatonin is tested in the treatment of neurodegenerative diseases as an antioxidant and neuroprotective agent (66-69). In patients with multiple sclerosis (MS), melatonin acts as an antioxidant and improves the reduced quality of sleep (66). The effect of melatonin on the expression of mRNA and sirtuin-1 (SIRT1) activity as well as its impact on superoxide dismutase 2 (MnSOD) and catalase activity in peripheral blood mononuclear cells (PBMC) in MS and healthy patients was investigated (59). Melatonin increases the activity and level of SIRT1 catalase mRNA in ill and healthy patients, whereas MnSOD increases only in patients with MS. A significant correlation was observed between the activity of SIRT1 and the catalase activity in PBMC of patients after treatment with melatonin. Melatonin can also relieve oxidative stress in neurodegenerative diseases such as Parkinson's disease (PD) (67). In the PD model, increased activity of antioxidant enzymes and plasma homocysteine reduction in plasma was shown due to homocysteine (Hcy PD model). Administration of melatonin may alleviate oxidative stress in the neurodegeneration process in the elderly (Xeroderma pigmentosum group A, XPA) (69). XPA modulates melatonin metabolism and circadian rhythm (68). The beneficial effects of melatonin in patients with Charcot-Marie-Tooth neuropathy (CMT) have also been shown to reduce the hyperoxidation and inflammatory state with which the reduction of the degenerative process may be associated (69).

Melatonin may act in a protective and therapeutic way to various diseases, including Sickle Cell Syndrome (SCA) (70). The level of melatonin was significantly lower in patients with SCA than in the control group. Patients with SCA showed a higher concentration of TBARS. Melatonin may in the future be a therapeutic target to improve antioxidant defense, and also to alleviate the symptoms of SCA.

The reported studies demonstrated the potential role of melatonin application against diseases of different etiologies (Table I).

\section{Antioxidative action in plants}

Melatonin plays a huge role in plant protection (84-106). It acts as an antioxidant and a signaling molecule that increases the abiotic resistance to stress in plants $(84,90,95,97-$ 106). It improves the tolerance of plants to heavy metals such as zinc, vanadium, cadmium and others. The study analyzed the response of watermelon seedlings to vanadium in a dose of $50 \mathrm{mg} \mathrm{L}^{-1}$ using melatonin $0.1 \mu \mathrm{mol} \mathrm{L}{ }^{-1}(84)$. Higher chlorophyll content, photosynthesis assimilation and plant growth were demonstrated in comparison with melatonin 


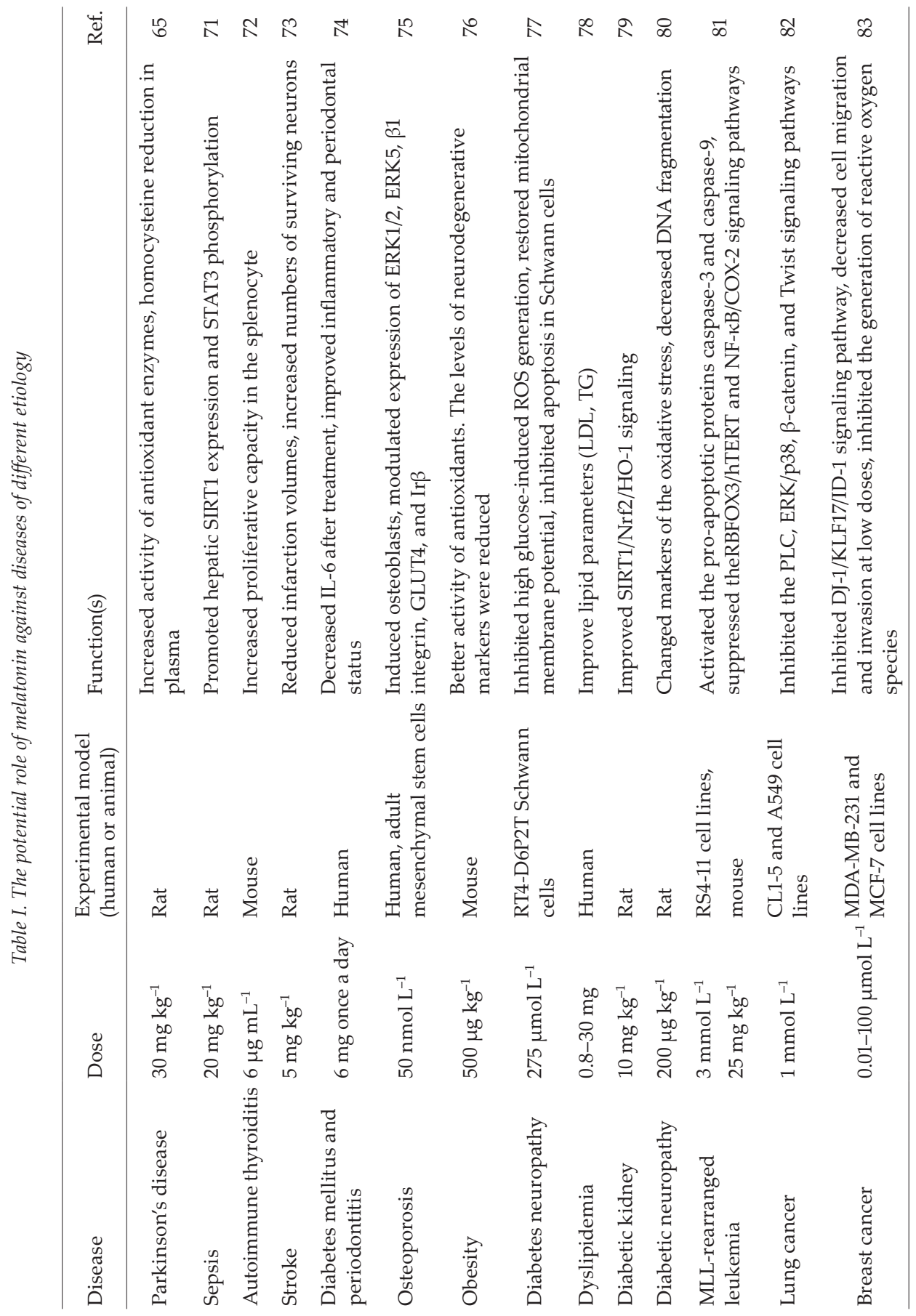


treated plants. Initial treatment with indoloamine reduced vanadium content in leaves and shoots by reducing the transport of heavy metal from root to stem. In addition, reduction of $\mathrm{H}_{2} \mathrm{O}_{2}$ and MDA in watermelon seedlings and enhancement of gene expression for SOD, peroxidase, ascorbic peroxidase, glutathione-S-transferase and GPx were also observed. Zhang et al. (85) conducted exogenous melatonin testing for browning in lychee after harvest. The fruit was treated with an aqueous solution of melatonin $\left(0.4 \mathrm{mmol} \mathrm{L}^{-1}\right)$ and stored at $25{ }^{\circ} \mathrm{C}$ for 8 days. Melatonin has severely inhibited browning of the pericardium and discoloration during storage. It inhibited the production of superoxide radicals, hydrogen peroxide, malondialdehyde. This substance delayed the loss of the total content of phenols, flavonoids and anthocyanins and enhanced the activity of antioxidant enzymes, i.e., superoxide dismutase (SOD), catalase (CAT), ascorbic peroxidase (APx) and glutathione reductase (GR), as well as reduced polyphenol oxidase activity (PPO) and peroxidase (POD). Melatonin delays the aging of kiwi leaves by activating antioxidant capacity and enhancement of flavonoid biosynthesis (86).

Melatonin plays a role in the improvement of germination, maturation, photosynthesis, biomass production, the circadian rhythm of membrane integrity, the development of root, leaf senescence, osmoregulation and abiotic stress (salt, drought, cold, heat, oxidation, heavy metals) (87). It induces gene expression which helps the plant cope with biotic and abiotic stress. The use of melatonin in post-harvest products is a very common material for research. Peaches were treated with $0.1 \mathrm{mmol} \mathrm{L}^{-1}$ melatonin and a slowdown in aging, increased activity of antioxidant enzymes and ascorbic acid content were observed $(87,88)$. In an abiotic environment in the absence of water deficiency, the addition of $200 \mu \mathrm{mol} \mathrm{L}-1$ melatonin resulted in changes in the activity of antioxidant enzymes (89).

The role of exogenous melatonin in the regulation of gene expression in plants is quite unknown today $(90,91)$. The studies showed that melatonin alleviated oxidative stress in apple leaves by decreasing the expression of the MdTDC1, MdT5H4, MdAANAT2, MdASMT1 genes and inhibited membrane damage and lipid peroxidation (90). Melatonin also protected tomatoes from salinity and heat by increasing the expression of the SlcAPx, SlGR1, SlGST, SlPh-GPX genes and activation of the antioxidant enzyme system (91). In turn, the indoleamine found in seeds presumably protects the embryo, remaining in a more or less dry environment in which the antioxidant enzymes cannot function effectively or be activated (2). Therefore, the role of a small molecule of melatonin as an effective antioxidant becomes important and is confirmed by its high content in herbs and other plants of the Alpine and Mediterranean region. These plants, exposed to extreme temperatures and UV radiation of considerable intensity, may use antioxidant properties (activation of the antioxidant enzyme system or elimination of ROS) to protect against damage caused by these factors. In addition, melatonin protects cucumber seeds and young seedlings from oxidative stress, by directly and indirectly detoxifying ROS, thanks to which plants grow better even in a harmful environment (92). Indoleamine causes the inhibition of leaf aging caused by darkness. This may be due to ROS uptake by activating the enzymatic antioxidative pathway catalyzed by SOD and reducing chlorophyll degradation (93). Melatonin relieves stress caused by the cold that caused oxidative stress by increasing ROS accumulation and reducing photosynthesis in tea leaves of Camellia sinensis L. Indoleamine reduced oxidative stress, strengthened the antioxidant potential and redox homeostasis, which as a consequence contributed to mitigating the adverse effect of cold on tea plants (94).

Table II presents recent research describing the effects of melatonin on the plants. 


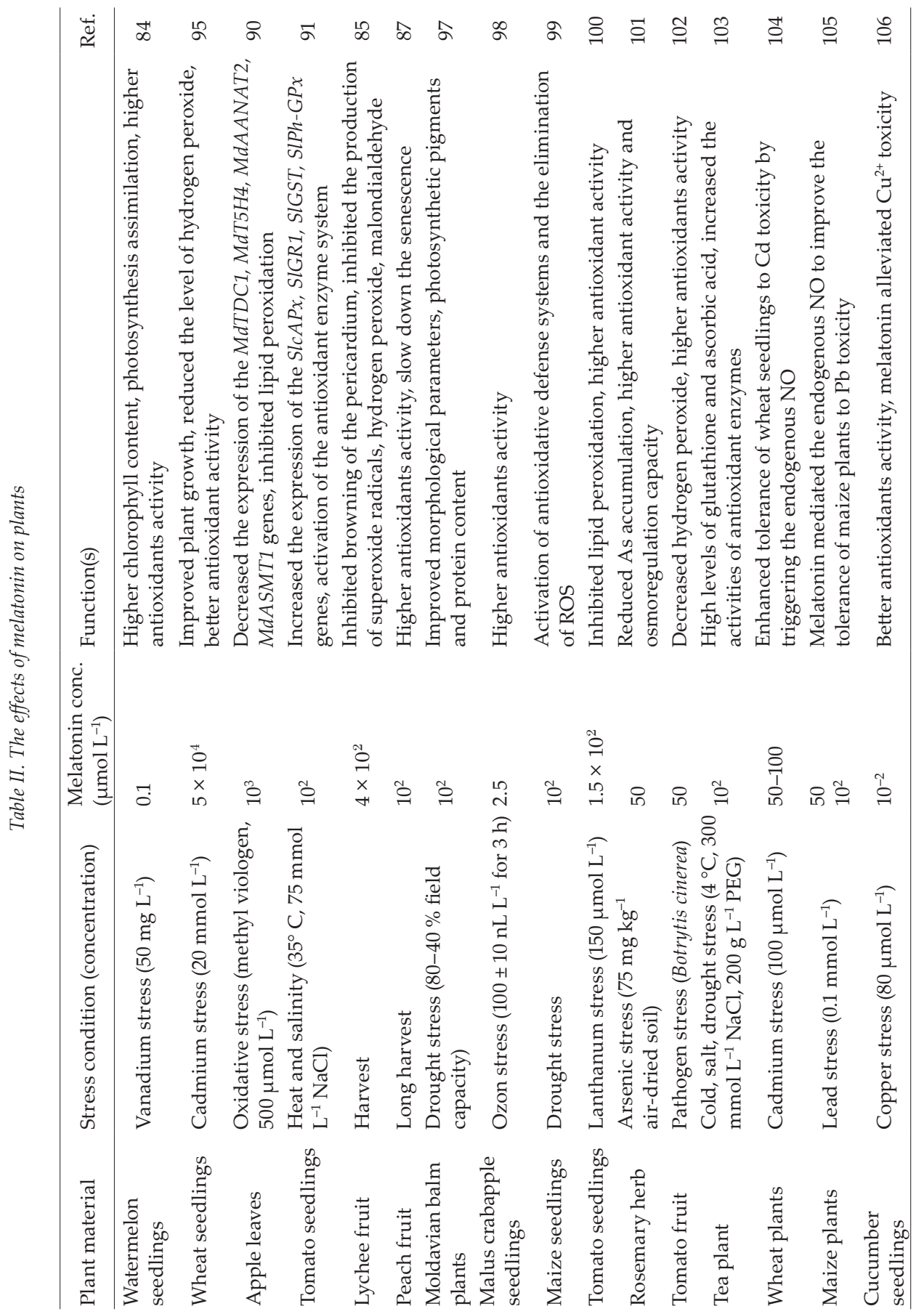




\section{CONCLUSIONS}

Melatonin is a widespread molecule that performs many functions in the body. It exhibits strong antioxidant properties in cell lines, animal models and humans, by activating antioxidant enzymes such as SOD, CAT, GPx. It protects cells from lipid peroxidation by reducing MDA and decreasing TBARS. Additionally, it neutralizes ROS and combats oxidative stress. Its antioxidant mechanisms are not thoroughly understood. As of today, it is known that melatonin works via melatonin receptors, nuclear receptors, directly with cytoplasmic proteins and activates the Nrf2-ARE pathway, and also affects NF- $\kappa$ B. Indoleamine is not indifferent to the processes of apoptosis, where it plays an enormous role in the pathways through changes in pro-apoptotic and anti-apoptotic proteins, in particular the $\mathrm{Bcl} 2 /$ Bax ratio, which may be important in the antioxidative process. Thanks to its antioxidant properties, melatonin can be successfully used in the treatment of diseases with free radical etiology, neurodegenerative diseases (Parkinson's disease, Alzheimer's disease, multiple sclerosis), diabetes, cardiovascular diseases, stroke, as well as cancers. Melatonin is unique in comparison to other signaling molecules not only due to the prevalence and variety of mechanisms involved in the transmission of the signal carried by it but also due to its antioxidant activity. Therefore, it is important to continue research on this amazing hormone in terms of antioxidant mechanisms and its use in the treatment of various diseases.

Abbreviations, acronyms, symbols. - AFMK - $N^{1}$-acetyl- $N^{2}$-formyl-5-methoxykynuramine; ALT alanine aminotransferase; AMK $-N^{1}$-acetyl-5-methoxykynuramine; ARE - elements of the antioxidant response; AST - aspartate aminotransferase; cAMP - cyclic adenosine monophosphate; CAT - catalase; cGMP - cyclic guanosine monophosphate; CNS - central nervous system; COX-2 - cyclooxygenase-2; DAG - diacylglycerol; DNA - deoxyribonucleic acid; GPCR - G-protein-coupled receptors; GPx glutathione peroxidase; GSH - glutathione (reduced form); GSSG - glutathione (oxidized form); GST glutathione S-transferase; Hcy - homocysteine; 4HDA - 4-hydroxyalkenals; HIOMT - hydroxyindole-O-methyl transferase; HO-1 - homooxygenase-1; IFN- - - gamma interferon; IL - interleukin; iNOS - inducible nitric oxide synthase; IP3 - inositol trisphosphate; IRI - ischemia-reperfusion injury; IкBalpha - nuclear factor of kappa light polypeptide gene enhancer in B-cells inhibitor, alpha; LDH - lactate dehydrogenase; MAPK - mitogen-activated protein kinase; MDA - malondialdehyde; MK-801 dizocilpine; MnSOD - superoxide dismutase 2 [SOD 2]; mPGES1 - microsomal prostaglandin E synthase-1; MPO - myeloperoxidase; mRNA - messenger RNA (ribonucleic acid); MS - multiple sclerosis; NAFLD - non-alcoholic fatty liver disease; NASH - non-alcoholic steatohepatitis; NAT - N-acetyltransferase; NF- $\kappa \mathrm{B}$ - nuclear factor kappa-light-chain-enhancer of activated B cells; NK cells - natural killer cells; NPC - neural precursor cells; NQO1 - NAD(P)H quinone dehydrogenase 1; NQO1 - quinone oxidoreductase; Nrf2 - nuclear factor erythroid 2-related factor 2; NSCs - neuronal stem cells; P13K - phoshatidylinositide-3 kinase; PBMCs - peripheral blood mononuclear cells; POD - peroxidase; $\mathrm{PPO}$ - polyphenol oxidase activity; ROR/RZR - retinoic acid receptor-related orphan receptor/retinoid $\mathrm{Z}$ receptor; $\mathrm{ROS}$ - reactive oxygen species; $\mathrm{SCA}$ - sickle cell syndrome; $\mathrm{SCN}$ - suprachiasmatic nucleus of the hypothalamus; SIRT1 - sirtuin-1; SOD - superoxide dismutase; SOD1 - superoxide dismutase 1 [Cu-ZnSOD]; Srx - sulfedoxine; TAC - total antioxidant capacity; TBARS - thiobarbituric acid reactive substances; TRAb - antibodies against the thyrotropin receptor; Txnrd - thioredoxin reductase

\section{REFERENCES}

1. M. Brzęczek, K. Słonka and L. Hyla-Klekot, Melatonin-a pleiotropic hormone, Pediatr. Med. Rodz. 12 (2016) 127-133; https://doi.org/ 10.15557/PiMR.2016.0011

2. K. Skwarło-Sońta and P. Majewski, Melatonin, multifunctional signal molecule in mammals: origin, functions, mechanisms of action, Folia Med. Lodziensia 37 (2010) 15-55. 
3. H. Illnerova, M. Buresova and J. Presl, Melatonin rhythm in human milk, J. Clin. Endocrinol. Metab. 77 (1993) 838-841; https://doi.org/10.1210/jcem.77.3.8370707.

4. D. Katzer, L. Pauli, A. Mueller, H. Reutter, J. Reinsberg, R. Fimmers, P. Bartmann and S. Bagci, Melatonin concentrations and antioxidative capacity of human breast milk according to gestational age and the time of day, J. Human Lact. 32 (2016) NP105-NP110, Article ID 5620613; https://doi. org/10.1177/0890334415625217

5. G. Huether, Melatonin synthesis in the gastrointestinal tract and the impact of nutritional factors on circulating melatonin, Ann. N. Y. Acad. Sci.31 (1994) 146-158; https://doi.org/10.1111/j.1749-6632.1994. tb56826.x

6. D. Acuna-Castroviejo, G. Escames, C. Venegas, M. E. Diaz-Casado, E. Lima-Cabello, L. C. Lopez, S. Rosales-Corral, D. Tan and R. J. Reiter, Extrapineal melatonin: sources, regulation, and potential functions, Cell. Mol. Life Sci. 71 (2014) 2997-3025; https://doi.org/10.1007/s00018-014-1579-2

7. P. T. Popławski and R. A. Derlacz, [How does melatonin function?] [Article in Polish] Post. Biochem. 49 (2003) 1-9.

8. M. Singh and H. R. Jadhav, Melatonin: functions and ligands, Drug Disc. Today 19 (2014) 1410-1418; https://doi.org/10.1016/j.drudis.2014.04.014

9. D. Tan, L. C. Manchester, E. Esteban-Zubero, Z. Zhou and R. J. Reiter, Melatonin as a potent and inducible endogenous antioxidant: Synthesis and metabolism, Molecules 20 (2015) 18886-18906; https://doi.org/10.3390/molecules201018886

10. M. Skalski, Melatonin in sleep disorders and disorders of the circadian rhythm, Farmakoter. Psych. Neurol. 98 (1998) 103-111.

11. M. Magierowski, K. Jasnos, I. Brzozowska, D. Drozdowicz, Z. Śliwowski, E. Nawrot, U. Szczyrk and S. Kwiecień, Melatonin as a therapeutic factor in gastric ulcer healing under experimental diabetes, Prz. Lek. 70 (2013) 942-946.

12. Y. Hong, J. Won, Y. Lee, S. Lee, K. Park, K. Changand and Y. Hon, Melatonin treatment induces interplay of apoptosis, autophagy, and senescence in human colorectal cancer cells, J. Pineal Res. 56 (2014) 264-274; https://doi.org/10.1111/jpi.12119

13. S. M. Hill, V. P. Belancio, R. T. Dauchy, S. Xiang, S. Brimer, L. Mao, A. Hauch, P. W. Lundberg, W. Summers, L. Yuan, T. Frasch and D. E. Blask, Melatonin: an inhibitor of breast cancer, Endocr. Relat. Cancer 22 (2015) Article ID 1024854; https://doi.org/10.1530/ERC-15-0030

14. E. A. Cohen, A. Hadash, N. Shehadeh and G. Pillar, Breastfeeding may improve nocturnal sleep and reduce infantile colic: potential role of breast milk melatonin, Eur. J. Pediatr. 171 (2012) 729-732; https://doi.org/10.1007/s00431-011-1659-3

15. J. E. Roberts, D. N. Hu, L. Martinez and C. F. Chignell, Photophysical studies on melatonin and its receptor agonists, J. Pineal Res. 29 (2000) 94-99; https://doi.org/10.1034/j.1600-079x.2000.290205.x

16. H. S. Mahal, H. S. Sharma and T. Mukherjee, Antioxidant properties of melatonin: a pulse radiolysis study, Free Radic. Biol. Med. 26 (1999) 557-565; https://doi.org/10.1016/s0891-5849(98)00226-3

17. M. Zhang, C. Gao, Y. Leak, R. K. Chen and J. Zhang, Emerging roles of Nrf2 and phase II antioxidant enzymes in neuroprotection, Progr. Neurobiol. 100 (2013) 30-47; https://doi.org/10.1016/j.pneurobio.2012.09.003

18. D. N. Tripathi and G. B. Jena, Effect of melatonin on the expression of Nrf2 and NF-kappaB during cyclophosphamide induced urinary bladder injury in rat, J. Pineal Res. 48 (2010) 324-331; https://doi. org/10.1111/j.1600-079X.2010.00756.x

19. J. Vriend and R. J. Reiter, The Keap1-Nrf2-antioxidant response element pathway: A review of its regulation by melatonin and the proteasome, Mol. Cell. Endocrinol. 401 (2015) 213-220; https://doi. org/10.1016/j.mce.2014.12.013

20. N. F. Villeneuve, A. Lau and D. D. Zhang, Regulation of the Nrf2-Keap1 antioxidant response by the ubiquitin-proteasome system: an insight into cullin-ring ubiquitin ligases, Antiox. Redox Signal. 13 (2010) 1699-1712; https://doi.org/10.1089/ars.2010.3211 
21. W. Deng, Q. Xu, Y. Liu, C. Jiang, H. Zhuoa and L. Gu, Effects of melatonin on liver function and lipid peroxidation in a rat model of hepatic ischemia/reperfusion injury, Exp. Ther. Med. 11 (2016) 1955-1960; https://doi.org/10.3892/etm.2016.3160

22. K. Ding, H. Wang, J. Xu, T. Li, L. Zhang, Y. Ding, L. Zhu, J. He and M. Zhou, Melatonin stimulates antioxidant enzymes and reduces oxidative stress in experimental traumatic brain injury: the Nrf2-ARE signaling pathway as a potential mechanism, Free Rad. Biol. Med. 73 (2014) 1-11; https:// doi.org/10.1016/j.freeradbiomed.2014.04.031

23. P. Rajputa, A. Jangrab, M. Kwatraa, A. Mishrac and M. Lahkard, Alcohol aggravates stress-induced cognitive deficits and hippocampal neurotoxicity: Protective effect of melatonin, Biomed. Pharmacother. 91 (2017) 457-466; https://doi.org/10.1016/j.biopha.2017.04.077

24. M. Aparicio-Soto, C. Alarcón-de-la-Lastra, A. Cárdeno, S. Sánchez-Fidalgo and M. Sanchez-Hidalg, Melatonin modulates microsomal PGE synthase 1 and NF-E2-related factor-2-regulated antioxidant enzyme expression in LPS-induced murine peritoneal macrophages, Br. J. Pharmacol. 171 (2014) 134-144; https://doi.org/10.1111/bph.12428

25. V. Brazao, R. P. Colato, F. H. Santello, G. T. do Vale, N. de Almeida Gonzaga, C. R. Tirapelli and J. C. do Prado, T. cruzi infection among aged rats: Melatonin as a promising therapeutic molecule, Exp. Gerontol. 135 (2020) Article ID 110922 (8 pages); https://doi.org/10.1016/j.exger.2020.110922

26. A. Kumar, S. Mehrotra, G. Singh, K. Narayanan, G. K. Das, Y.K. Soni, M. Singh, A. S. Mahla, N. Srivastava and M. R. Verma, Sustained delivery of exogenous melatonin influences biomarkers of oxidative stress and total antioxidant capacity in summer-stressed anestrous water buffalo (Bubalus bubalis), Theriogenology 83 (2015) 1402-1407; https://doi.org/10.1016/j.theriogenology.2014.12.023

27. M. Guney, B. Oral, N. Karahan and T. Mungan, Regression of endometrial explants in a rat model of endometriosis treated with melatonin, Fertil. Steril. 89 (2008) 934-942; https://doi.org/10.1016/j. fertnstert.2007.04.023

28. M. Allegra, R. J. Reiter, D.-X. Tan, C. Gentile, L. Tesoriere and M. A. Livrea, The chemistry of melatonin's interaction with reactive species, J. Pineal Res. 34 (2003) 1-10 (10 pages); https://doi.org/10.1034/ j.1600-079x.2003.02112.x

29. D. Onk, O. A. Onk, H. S. Erol, M. Özkaraca, S. Çomaklı, T. A. Ayazoğlu, U. Kuyrukluyıldız and S. Ünver, Effect of melatonin on antioxidant capacity, inflammation and apoptotic cell death in lung tissue of diabetic rats, Acta Cir. Bras. 33 (2018) 375-385; https://doi.org/10.1590/s0102865020180040000009

30. S. Ozdinc, G. Oz, C. Ozdemir, I. Kilic, Z. Karakaya, A. Bal, T. Koken and O. Solak, Melatonin: is it an effective antioxidant for pulmonary contusion?, J. Surg. Res. 204 (2016) 445-451; https://doi. org/10.1016/j.jss.2016.05.020

31. P. K. Choudhary, A. K. Ishwar, R. Kumar, D. Niyogi and M. Kumar, Effect of exogenous melatonin and different photoperiods on oxidative status and antioxidant enzyme activity in Chhotanagpuri, Vet. World 11 (2018) 130-134; https://doi.org/10.14202/vetworld.2018.130-134

32. K. Mortezaee and N. Khanlarkhani, Melatonin application in targeting oxidative-induced liver injuries: A review, J. Cell. Physiol. 233 (2018) 4015-4032; https://doi.org/10.1002/jcp.26209

33. H. H. Chen, Y. T. Chen, C. C. Yang, K. H Chen, P. H., Sung, H. J Chiang and Y. L. Chen, Melatonin pretreatment enhances the therapeutic effects of exogenous mitochondria against hepatic ischemia-reperfusion injury in rats through suppression of mitochondrial permeability transition, J. Pineal Res. 61 (2016) 52-68; https://doi.org/10.1111/jpi.12326

34. R. Kireev, S. Bitoun, S. Cuesta, A. Tejerina, C. Ibarrola, E. Moreno and J. A. Tresguerres, Melatonin treatment protects liver of Zucker rats after ischemia/reperfusion by diminishing oxidative stress and apoptosis, Eur. J. Pharmacol. 701 (2013) 185-193; https://doi.org/10.1016/j.ejphar.2012.11.038

35. J. R. Colares, E. G. Schemitt, R. M. Hartmann, F. Licks, M. do Couto Soares, A. Dal Bosco and N. P. Marroni, Antioxidant and anti-inflammatory action of melatonin in an experimental model of secondary biliary cirrhosis induced by bile duct ligation, World J. Gastroenterol. 22 (2016) 8918-8928; https://doi.org/10.3748/wjg.v22.i40.8918 
36. W. Deng, Q. Xu, Y. Liu, Ch. Jiang, H. Zhou and L. Gu, Effects of melatonin on liver function and lipid peroxidation in a rat model of hepatic ischemia/reperfusion injury, Exp. Ther. Med. 11 (2016) 1955-1960; https://doi.org/10.3892/etm.2016.3160

37. G. Rao, R. Verma, A. Mukherjee, Ch. Haldar and N. Kumar, Melatonin alleviates hyperthyroidism induced oxidative stress and neuronal cell death in hippocampus of aged female golden hamster, Mesocricetus auratus, Agrawa Exp. Gerontol. 82 (2016) 125-130; https://doi.org/10.1016/j. exger.2016.06.014

38. C. Carrasco, A. B. Rodríguez and J. A. Pariente, Effects of melatonin on the oxidative damage and pancreatic antioxidant defenses in cerulein-induced acute pancreatitis in rats, Hepatobil. Pancreat. Dis. Int. 13 (2014) 442-446; https://doi.org/10.1016/s1499-3872(14)60271-x

39. A. Ahsen, Y. Gonul, A. Genc, M. S. Ulu, M. Yagmurca, C. U. Kocogullari, S. Celik and S. Yuksel, Protective effect of melatonin on infrarenal aortic occlusion: This effect is related to anti-inflammatory effect and antioxidant effect, Inflammation 37 (2014) 1111-1119; https://doi.org/10.1007/s10753-0149835-z

40. O. Karabulut-Bulan, B. B. Bayrak, P. Arda-Pirincci, G. Sarikaya-Unal, H. Us and R. Yanardag, Role of exogenous melatonin on cell proliferation and oxidant/antioxidant system in aluminum-induced renal toxicity, Biol. Trace Elem. Res. 168 (2015) 141-149; https://doi.org/10.1007/s12011-015-0320-9.

41. Z. Donmez, O. Yigit, S. Bilici, N. Dursun, M. Gul, S. D. Dastan and S. Uzun, Evaluation of the antioxidant effects of melatonin on the larynx mucosa of rats exposed to environmental tobacco smoke, Clin. Otolaryngol. 41 (2016) 211-221; https://doi.org/10.1111/coa.12501

42. M. Montiel, E. Bonilla, N. Valero, J. Mosquera, L. M. Espina, Y. Quiroz and M. Álvarez-Mon, Melatonin decreases brain apoptosis, oxidative stress, and CD200 expression and increased survival rate in mice infected by Venezuelan equine encephalitis virus, Antivir. Chem. Chemother. 24 (2015) 99-108; https://doi.org/10.1177/2040206616660851

43. H. He, W. Dong and F. Huang, Anti-amyloidogenic and anti-apoptotic role of melatonin in Alzheimer disease, Curr. Neuropharmacol. 8 (2010) 211-217; https://doi.org/10.2174/157015910792246137

44. N. Watson, T. Diamandis, Ch. Gonzales-Portillo, S. Reyes and C. V. Borlongan, Melatonin as an antioxidant for stroke neuroprotection, Cell Transplant. 25 (2016) 883-891; https://doi. org/10.3727/096368915X689749

45. H. Ozyurt, B. Ozyurt, M. Sarsilmaz, I. Kus, A. Songur and O. Akyo, Potential role of some oxidant/ antioxidant status parameters in prefrontal cortex of rat brain in an experimental psychosis model and the protective effects of melatonin, Eur. Rev. Med. Pharmacol. Sci. 18 (2014) 2137-2144.

46. R. Li, X. Luo, L. Li, Q. Peng. Y. Yang, L. Zhao, M. Ma and Z. Hou, The protective effects of melatonin against oxidative stress and inflammation induced by acute cadmium exposure in mice testis, Biol. Trace Elem. Res. 170 (2016) 152-164; https://doi.org/10.1007/s12011-015-0449-6

47. X. Pan, L. Zhu, H. Lu, D. Wang, Q. Lu and H. Yan, Melatonin attenuates oxidative damage induced by acrylamide in vitro and in vivo, oxidative medicine and cellular longevity, 2015 (2015) Article ID 703709 (12 pages); https://doi.org/10.1155/2015/703709

48. M. Bazrgar, I. Goudarzi, T. Lashkarbolouki and M. E. Salmani, Melatonin ameliorates oxidative damage induced by maternal lead exposure in rat pups, Physiol. Behav. 151 (2015) 178-188; https:// doi.org/10.1016/j.physbeh.2015.06.040

49. F. Bagheri, I. Goudarzi, T. Lashkarbolouki and M. E. Salman, Melatonin prevents oxidative damage induced by maternal ethanol administration and reduces homocysteine in the cerebellum of rat pups, Behav. Brain Res. 287 (2015) 215-225; https://doi.org/10.1016/j.bbr.2015.03.022

50. S. Goswami and Ch. Haldar, UVB irradiation severely induces systemic tissue injury by augmenting oxidative load in a tropical rodent: Efficacy of melatonin as an antioxidant, J. Photochem. Photobiol. B 141 (2014) 84-92; https://doi.org/10.1016/j.jphotobiol.2014.08.027

51. D. Sokolovic, B. Djordjevic, G. Kocic, T. J. Stoimenov, Z. Stanojkovic, D. M. Sokolovic, A. Veljkovic, G. Ristic, M. Despotovic, D. Milisavljevic, R. Jankovic and I. Binic, The effects of melatonin on oxida- 
tive stress parameters and dna fragmentation in testicular tissue of rats exposed to microwave radiation, Adv. Clin. Exp. Med. 24 (2015) 429-436; https://doi.org/10.17219/acem/43888

52. T. Shua, L. Fana, T. Wub, Ch. Liua, L. Hea, M. Panga, Y. Bua, X. Wanga, J. Wangc, L. Ronga and B. Liua, Melatonin promotes neuroprotection of induced pluripotent stem cells-derived neural stem cells subjected to $\mathrm{H}_{2} \mathrm{O}_{2}$-induced injury in vitro, Eur. J. Pharmacol. 825 (2018) 143-150: https://doi. org/10.1016/j.ejphar.2018.02.027

53. P. Wongprayoon and P. Govitrapong, Melatonin protects $\mathrm{SH}_{-} \mathrm{SY}_{5} \mathrm{Y}$ neuronal cells against methamphetamine-induced endoplasmic reticulum stress and apoptotic cell death, Neurotox. Res. 31 (2017) 1-10; https://doi.org/10.1007/s12640-016-9647-z

54. Ch. Chang, T. Huang, H. Chen, T. Huang, L. Lin, Y. Chang and S. Hsia, Protective effect of melatonin against oxidative stress-induced apoptosis and enhanced autophagy in human retinal pigment epithelium, Oxid. Med. Cell. Longev. 2018 (2018) Article ID 9015765 (12 pages); https://doi. org/10.1155/2018/9015765

55. R. He, M. Cui, H. Lin, L. Zhao, J. Wang, S. Chen and Z. Shao, Melatonin resists oxidative stress-induced apoptosis in nucleus pulposus cells, Life Sci. 199 (2018) 122-130; https://doi.org/10.1016/j. lfs.2018.03.020

56. D. Zhu, Y. Ma, S. Ding, H. Jiang and J. F. Hindawi, Effects of melatonin on intestinal microbiota and oxidative stress in colitis mice, BioMed Res. Int. 2018 (2018) Article ID 2607679 (6 pages); https://doi. org/10.1155/2018/2607679

57. A. Carpentieri, A. Marchionatti, V. Areco, A. Perez, V. Centeno and N. Tolosa de Talamoni, Antioxidant and antiapoptotic properties of melatonin restore intestinal calcium absorption altered by menadione, Mol. Cell. Biochem. 387 (2014) 197-205; https://doi.org/10.1007/s11010-013-1885-2

58. A. K. Singh and Ch. Haldar, Melatonin modulates glucocorticoid receptor mediated inhibition of antioxidant response and apoptosis in peripheral blood mononuclear cells, Mol. Cell. Endocrinol. 436 (2016) 59-67; https://doi.org/10.1016/j.mce.2016.07.024

59. S. Emamgholipour, A. Hossein-Nezhad and M. Ansari, Can melatonin act as an antioxidant in hydrogen peroxide-induced oxidative stress model in human peripheral blood mononuclear cells, Biochem. Res. Int. 2016 (2016) Article ID 2527940 (8 pages); https://doi.org/ 10.1155/2016/5857940

60. A. Sánchez-Bretaño, K. Baba, U. Janjua, I. Piano, C. Gargini and G. Tosini, Melatonin partially protects $661 \mathrm{~W}$ cells from $\mathrm{H}_{2} \mathrm{O}_{2}$-induced death by inhibiting Fas/FasL-caspase-3, Mol. Vision 23 (2017) 844-852.

61. M. Koziróg, A. R. Poliwczak, P. Duchnowicz, M. Koter-Michalak, J. Sikora and M. Broncel, Melatonin treatment improves blood pressure, lipid profile, and parameters of oxidative stress inpatients with metabolic syndrome, J. Pineal Res. 50 (2011) 261-266; https://doi. org/10.1111/j.1600-079X.2010.00835.x

62. K. Szewczyk-Golec, P. Rajewski, M. Gackowski, C. Mila-Kierzenkowska, R. Wesołowski, P. Sutkowy, M. Pawłowska and A. Woźniak, Melatonin supplementation lowers oxidative stress and regulates adipokines in obese patients on a calorie-restricted diet, Oxid. Med. Cell. Longev. 2017 (2017) Article ID 8494107 (10 pages); https://doi.org/10.1155/2017/8494107

63. N. M. Alamdari, R. Mahdavi, N. Roshanravan, N. L. Yaghin, A. R. Ostadrahimi and E. Faramarzi, A double-blind, placebo-controlled trial related to the effects of melatonin on oxidative stress and inflammatory parameters of obese women, Horm. Metab. Res. 47 (2015) 504-508; https://doi. org/10.1055/s-0034-1384587

64. K. Kedziora-Kornatowska, K. Szewczyk-Golec, M. Kozakiewicz, H. Pawluk, J. Czuczejko, T. Kornatowski, G. Bartosz and J. Kedziora, Melatonin improves oxidative stress parameters measured in the blood of elderly type 2 diabetic patients, J. Pineal Res. 46 (2009) 333-337; hhtps:// https://doi. org/10.1111/j.1600-079X.2009.00666.x

65. J. Rybka, K. Kędziora-Kornatowska, D. Kupczyk, M. Muszalik, M. Kornatowski and J. Kędziora, Antioxidant effect of immediate- versus sustainedrelease melatonin in type 2 diabetes mellitus and healthy controls, Drug Deliv. 23 (2016) 804-807; https://doi.org/ 10.3109/10717544.2014.917343 
66. M. Adamczyk-Sowa, K. Pierzchala, P. Sowa, S. Mucha, I. Sadowska-Bartosz, J. Adamczyk and M. Hartel, Melatonin acts as antioxidant and improves sleep in MS patients, Neurochem. Res. 39 (2014) 1585-1593; https://doi.org/10.1007/s11064-014-1347-6

67. R. Paula, B. C. Phukana, A. J. Thenmozhic, T. Manivasagamc, P. Bhattacharyad and A. Borah, Melatonin protects against behavioral deficits, dopamine loss and oxidative stress in homocysteine model of Parkinson's disease, Life Sci. 192 (2018) 238-245; https://doi.org/10.1016/j.lfs.2017.11.016

68. R. Miyata, N. Tanuma, H. Sakuma and M. Hayashi, Circadian rhythms of oxidative stress markers and melatonin metabolite in patients with xeroderma pigmentosum group A, Oxid. Med. Cell. Longev. 2016 (2016) Article ID 5741517 (5 pages); https://doi.org/10.1155/2016/5741517

69. M. Chahbouni, M. Del Señor López, A. Molina-Carballo, T. De Haro, A. Muñoz-Hoyos, M. Fernández-Ortiz, A. Guerra-Librero and D. Acuña-Castroviejo, Melatonin treatment reduces oxidative damage and normalizes plasma pro-inflammatory cytokines in patients suffering from CharcotMarie-Tooth neuropathy: A pilot study in three children, Molecules 22 (2017) Article ID 1728 (14 pages); https://doi.org/10.3390/molecules22101728

70. E. Litsuko, T. Shimauti, D. G. H. Silva, E. Alves de Almeida, P. J. A. Zamaro, E. Belini and C. R. Bonini-Domingos, Serum melatonin level and oxidative stress in sickle cell anemia, Blood Cell. Mol. Dis. 45 (2010) 297-301; https://doi.org/10.1016/j.bcmd.2010.08.013

71. J. Chen, H. Xian, L. Zhang, H. Zhang, D. Wang and X. Tao, Protective effects of melatonin on sepsisinduced liver injury and dysregulation of gluconeogenesis in rats through activating SIRT1/STAT3 pathway, Biomed. Pharmacother. 117 (2019) Article ID 109150 (8 pages); https://doi.org/10.1016/j.biopha.2019.109150

72. J.-D. Lin, W.-F. Fang, K.-T. Tang and C.-W. Cheng, Effects of exogenous melatonin on clinical and pathological features of a human thyroglobulin-induced experimental autoimmune thyroiditis mouse model, Sci. Rep. 9 (2019) Article ID 5886 (12 pages); https://doi.org/10.1038/s41598-019-42442-0

73. Y. W. Lin, T. Y. Chen, C. Y. Hung, S. H. Tai, S. Y. Huang, C. C. Chang, H. Y. Hung and E. J. Lee, Melatonin protects brain against ischemia/reperfusion injury by attenuating endoplasmic reticulum stress, Int. J. Mol. Med. 42 (2018) 182-192; https://doi.org/10.3892/ijmm.2018.3607

74. H. Bazyar, H. Gholinezhad, L. Moradi, P. Salehi, F. Abadi, M. Ravanbakhsh and Z. A. Javid, The effects of melatonin supplementation in adjunct with non-surgical periodontal therapy on periodontal status, serum melatonin and inflammatory markers in type 2 diabetes mellitus patients with chronic periodontitis: a double-blind, placebo-controlled trial, Inflammopharmacology 27 (2019) 67-76; https://doi.org/10.1007/s10787-018-0539-0

75. M. Sifat, R. M. Samsonraj, F. Munmun, J. Glas, M. Silvestros, M. P. Kotlarczyk, R. Rylands, A. Dudakovic, A. J. van Wijnen, L. T. Enderby, H. Lassila, B. Dodda, V. L. Davis, J. Balk, M. Burow, B. A. Bunnell and P. A. Witt-Enderby, Biological effects of melatonin on osteoblast/osteoclast cocultures, bone, and quality of life: Implications of a role for MT2 melatonin receptors, MEK1/2, and MEK5 in melatonin-mediated osteoblastogenesis, J. Pineal Res. 64 (2018) e12465 (40 pages); https://doi. org/10.1111/jpi.12465

76. A. Rubio-González, J. C. Bermejo-Millo, B. de Luxán-Delgado, Y. Potes, Z. Pérez-Martínez, J. A. Boga, I. Vega-Naredo, B. Caballero, J. J. Solano and A. Coto-Montes, Melatonin prevents the harmful effects of obesity on the brain, including at the behavioral level, Mol. Neurobiol. 55 (2018) 5830 5846; https://doi.org/10.1007/s12035-017-0796-8

77. Y. L. Tiong, K. Y. Ng, R. Y. Koh, G. Ponnudurai and S. M. Chye, Melatonin prevents oxidative stress-induced mitochondrial dysfunction and apoptosis in high glucose-treated Schwann cells via upregulation of Bcl2, NF-kB, mTOR, Wnt signalling pathways, Antioxidants (Basel) 8 (2019) Article ID 198 (15 pages); https://doi.org/10.3390/antiox8070198

78. S. Loloei, M. Sepidarkish, A. Heydarian, N. Tahvilian, M. Khazdouz, J. Heshmati and H. Pouraram, The effect of melatonin supplementation on lipid profile and anthropometric indices: A systematic review and meta-analysis of clinical trials, Diabetes Metab. Syndr. 13 (2019) 1901-1910; https:// doi.org/10.1016/j.dsx.2019.04.043 
79. S. Shi, S. Lei, C. Tang, K Wang and Z. Xia, Melatonin attenuates acute kidney ischemia/reperfusion injury in diabetic rats by activation of the SIRT1/Nrf2/HO-1 signaling pathway, Biosci. Rep. 15 (2019) Article ID BSR20181614 (13 pages); https://doi.org/10.1042/BSR20181614

80. T. K. Motawi, S. A. Ahmed, M. A. Hamed, S. A. El-Maraghy and W. M. Aziz, Melatonin and/or rowatinex attenuate streptozotocin-induced diabetic renal injury in rats, J. Biomed. Res. 33 (2019) 113-121; https://doi.org/10.7555/JBR.31.20160028

81. Y. L. Tang, X. Sun, L. B. Huang, X. J. Liu, G. Qin, L. N. Wang, X. L. Zhang, Z. Y. Ke, J. S. Luo, C. Liang, C. J. Peng, W. Y. Tang, Y. Li, W. Huang, X. Q. Luo and W. Deng, Melatonin inhibits MLL-rearranged leukemia via RBFOX3/hTERT and NF-кB/COX-2 signaling pathways, Cancer Lett. 28 (2019) 167-178; https://doi.org/10.1016/j.canlet.2018.11.037

82. Y. C. Yang, P. C. Chiou, P. C. Chen, P. Y. Liu, W. C. Huang, C. C. Chao and C. H. Tang, Melatonin reduces lung cancer stemness through inhibiting of PLC, ERK, p38, $\beta$-catenin, and twist pathways, Environ. Toxicol. 34 (2019) 203-209; https://doi.org/ 10.1002/tox.22674

83. G. H. El-Sokkary, I. A. Ismail and S. H. Saber, Melatonin inhibits breast cancer cell invasion through modulating DJ-1/KLF17/ID-1 signaling pathway, J. Cell. Biochem. 120 (2019) 3945-3957; https://doi. org/10.1002/jcb.27678

84. M. A. Nawaz, Y. Jiaoa, Ch. Chena, F. Shireena, Z. Zhenga, M. Imtiazc, Z. Biea and Y. Huanga, Melatonin pretreatment improves vanadium stress tolerance of watermelon seedlings by reducing vanadium concentration in the leaves and regulating melatonin biosynthesis and antioxidant-related gene expression, J. Plant Physiol. 220 (2018) 115-127; https://doi.org/10.1016/j.jplph.2017.11.003

85. Y. Zhang, D. J. Huber, M. Hu, G. Jiang, Z. Gao, X. Xu, Y. Jiang and Z. Zhan, Delay of postharvest browning in litchi fruit by melatonin via the enhancing of antioxidative processes and oxidation repair, J. Agric. Food Chem. 66 (2018) 7475-7484; https://doi.org/10.1021/acs.jafc.8b01922.

86. D. Liang, Y. Shen, Z. Ni, Q. Wang, Z. Lei, N. Xu, Q. Deng, L. Lin, J. Wang, X. Lv and H. Xia, Exogenous melatonin application delays senescence of kiwifruit leaves by regulating the antioxidant capacity and biosynthesis of flavonoids, Front. Plant Sci. 9 (2018) Article ID 426 (14 pages); https://doi. org/10.3389/fpls.2018.00426

87. S. Cao, K. Bian, L. Shi, H. Chung, W. Chen and Z. Yang, Role of melatonin in cell-wall disassembly and chilling tolerance in cold-stored peach fruit, J. Agric. Food Chem. 66 (2018) 5663-5670; https://doi. org/10.1021/acs.jafc.8b02055

88. H. Gao, Z. Zhang, H.K. Chai, N. Cheng, Y. Yang, D. N. Wang, T. Yang and W. Cao, Melatonin treatment delays postharvest senescence and regulates reactive oxygen species metabolism in peach fruit, Postharvest Biol. Technol. 118 (2016) 103-110; https://doi.org/10.1016/j.postharvbio.2016.03.006

89. J. F. Meng, T.F. Xu, Z. Z. Wang, Y. L. Fang, Z. M. Xi and Z. W. Zhang, The ameliorative effects of exogenous melatonin on grape cuttings under water-deficient stress: antioxidant metabolites, leaf anatomy, and chloroplast morphology, J. Pineal Res. 57 (2014) 200-212; https://doi.org/10.1111/ jpi.12159

90. Y. Wei, G. Liu, Y. Chang, D. Lin, R. J. Reiter, C. He and H. Shi, Melatonin biosynthesis enzymes recruit WRKY transcription factors to regulate melatonin accumulation and transcriptional activity on W-box in cassava, J. Pineal Res. 65 (2018) Article ID 2487 (13 pages); https://doi.org/10.1111/ jpi.12487

91. V. Martinez, M. Nieves-Cordones, M. Lopez-Delacalle, R. Rodenas, T. C. Mestre, F. Garcia-Sanchez, F. Rubio, P. A. Nortes, R. Mittler and R. M. Rivero, Tolerance to stress combination in tomato plants: New insights in the protective role of melatonin, Molecules 23 (2018) Article ID 535 (20 pages); https:// doi.org/10.3390/molecules23030535

92. M. Bałabusta, K. Szafrańska and M. M. Posmyk, Exogenous melatonin improves antioxidant defense in cucumber seeds (Cucumis sativus L.) germinated under chilling stress, Front. Plant Sci. 7 (2016) 575-589; https://doi.org/10.3389/fpls.2016.00575 
93. J. Zhang, L. Huibin, B. Xu, J. Li and B. Huang, Exogenous melatonin suppresses dark-induced leaf senescence by activating the superoxide dismutase-catalase antioxidant pathway and down-regulating chlorophyll degradation in excised leaves of perennial ryegrass (Lolium perenne L.), Front. Plant Sci. 7 (2016) 1500 (15 pages); https://doi.org/10.3389/fpls.2016.01500

94. X. Li, J.-P. Wei, E. R. Scott, J.-W. Liu, S. Guo, Y. Li, L. Zhang and W.-Y. Han, Exogenous melatonin alleviates cold stress by promoting antioxidant defense and redox homeostasis in Camellia sinensis L., Molecules 23 (2018) Article ID 165 (10 pages); https://doi.org/10.3390/molecules23010165

95. J. Ni, Q. Wang, F. A. Shah, W. Liu, D. Wang, S. Huang, S. Fu and L. Wu, Exogenous melatonin confers cadmium tolerance by counterbalancing the hydrogen peroxide homeostasis in wheat seedlings, Molecules 23 (2018) 799 (17 pages); https://doi.org/10.3390/molecules23040799

96. S. Cao, K. Bian, L. Shi, H. H. Chung, W. Chen and Z. Yang, Role of melatonin in cell-wall disassembly and chilling tolerance in cold-stored peach fruit, J. Agric. Food Chem. 66 (2018) 5663-5670; https://doi.org/10.1021/acs.jafc.8b02055

97. M. Naghizadeh, R. Kabiri, A. Hatami, H. Oloumi, F. Nasibi and Z. Tahmasei, Exogenous application of melatonin mitigates the adverse effects of drought stress on morpho-physiological traits and secondary metabolites in Moldavian balm (Dracocephalum moldavica), Physiol. Mol. Biol. Plants 25 (2019) 881-894; https://doi.org/10.1007/s12298-019-00674-4

98. Y. Qiu, K. An, J. Sun, X. Chen, X. Gong, L. Ma, S. Wu, S. Jiang, Z. Zhang and Y. Wang, Investigating the effect of methyl jasmonate and melatonin on resistance of Malus crabapple 'Hong Jiu' to ozone stress, Environ. Sci. Pollut. Res. Int. 26 (2019) 27761-27768; https://doi.org/10.1007/s11356-01905946-w

99. B. Huang, Y. E. Chen, Y. Q. Zhao, C. B. Ding, J. Q. Liao, C. Hu, L. J. Zhou, Z. W. Zhang, S. Yuan and M. Yuan, Exogenous melatonin alleviates oxidative damages and protects photosystem ii in maize seedlings under drought stress, Front. Plant Sci. 10 (2019) Article ID 677 (16 pages); https:// doi.org/10.3389/fpls.2019.0067

100. M. H. Siddiqui, S. Alamri, Q. D. Alsubaie, H. M. Ali, A. A. Ibrahim and A. Alsadon, Potential roles of melatonin and sulfur in alleviation of lanthanum toxicity in tomato seedlings, Ecotoxicol. Environ. Saf. 180 (2019) 656-667; https://doi.org/10.1016/j.ecoenv.2019.05.043

101. S. Farouk and S. M. Al-Amri, Exogenous melatonin-mediated modulation of arsenic tolerance with improved accretion of secondary metabolite production, activating antioxidant capacity and improved chloroplast ultrastructure in rosemary herb, Ecotoxicol. Environ. Saf. 180 (2019) 333-347; https://doi.org/10.1016/j.ecoenv.2019.05.021

102. C. Liu, L. Chen, R. Zhao, R. Li, S. Zhang, W. Yu, J. Sheng and L. Shen, Melatonin induces disease resistance to Botrytis cinerea in tomato fruit by activating jasmonic acid signaling pathway, J. Agric. Food Chem. 67 (2019) 6116-6124; https://doi.org/10.1021/acs.jafc.9b00058

103. J. Li, Y. Yang, K. Sun, Y. Chen, X. Chen and X. Li, Exogenous melatonin enhances cold, salt and drought stress tolerance by improving antioxidant defense in tea plant (Camellia sinensis $\mathrm{L}$., $\mathrm{O}$. Kuntze), Molecules 24 (2019) Article ID 1826 (14 pages); https://doi.org/10.3390/molecules24091826.

104. C. Kaya, M. Okant, F. Ugurlar, M. N. Alyemeni, M. Ashraf and P. Ahmad, Melatonin-mediated nitric oxide improves tolerance to cadmium toxicity by reducing oxidative stress in wheat plants, Chemosphere 225 (2019) 627-638; https://doi.org/10.1016/j.chemosphere.2019.03.026

105. M. Okant and C. Kaya, The role of endogenous nitric oxide in melatonin-improved tolerance to lead toxicity in maize plants, Environ. Sci. Pollut. Res. Int. 26 (2019) 11864-11874; https://doi. org/10.1007/s11356-019-04517-3.

106. Y. Y. Cao, C. D. Qi, S. Li, Z. Wang, X. Wang, J. Wang, S. Ren, X. Li, N. Zhang and Y. D. Guo, Melatonin alleviates copper toxicity via improving copper sequestration and ROS scavenging in cucumber, Plant Cell. Physiol. 60 (2019) 562-574; https://doi.org/10.1093/pcp/pcy226 